\title{
An Analysis of Bi-directional \\ Use of Frequencies for Satellite Communications
}

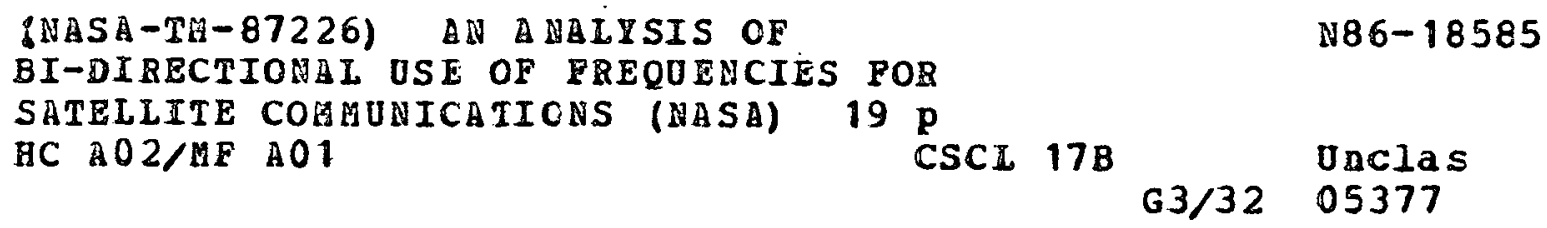

Wayne A. Whyte, Jr. and Edward F. Miller

Lewis Research Center

Cleveland, Ohio

and

Thomas Sullivan and John E. Miller ORI, Inc.

Landover, Maryland

Prepared for the

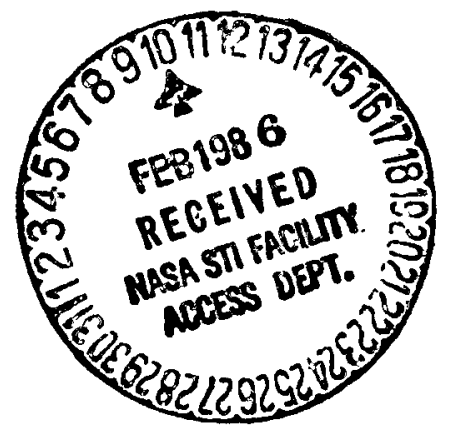

11th Annual Communications Satellite Systems Conference sponsored by the American Institute of Aeronautics and Astronautics San Diego, California, March 16-20, 1986

\section{N/Sก}


AN ANALYSIS OF BI-DIRECTIONAL USE OF FREQUENCIES FOR SATELLITE COMMUNICATIONS

\author{
Wayne A. Whyte, Jr. and Edward F. Miller \\ National Aeronautics and Space Administration \\ Lewis Research Center \\ - Cleveland, Ohio 44135 \\ Thomas Sullivan and John E. Miller \\ ORI, Inc. \\ Landover, Maryland 20785
}

\section{Abstract}

The bi-directional use of frequencies allocated for space communications has the potential to double the orbit/spectrum capacity available. This study examines the technical feasibility of reverse barid use (RBU) at $\mathrm{C}$-band ( $4 \mathrm{GHz}$ uplinks and $6 \mathrm{GHz}$ downlinks). The analysis identifies the constraints under which both forward and reverse band use satellite systems can share the same frequencies with terrestrial, line of sight transmission systems. The results of the analys is show that RBU satellite systems can be similarly sized to forward band use (FBU) satellite systems. In addition, the orbital separation requirements between RBU and FBU satellite systems are examined. The analysis shows that there are no unsolveable technical problems.

The analysis shows that a carrier to interference ratio of $45 \mathrm{~dB}$ can be maintained between RBU and FBU satellites separated by less than $0.5^{\circ}$, and that a carrier to interference ratio of $42 \mathrm{~dB}$ can be maintained in the antipodal case. Rain scatter propagation analysis shows that RBU and FBU earth stations require separation distances of less. than $10 \mathrm{~km}$ at a rain rate of $13.5 \mathrm{~mm} / \mathrm{hr}$ escalating to less than $100 \mathrm{~km}$ at a rain rate of $178 \mathrm{~mm} / \mathrm{hr}$ for earth station antennas in the 3 to $10 \mathrm{~m}$ range. The analysis also shows that the present interference limits for stations in the fixed service sharing allocations with the FSS are adequate to protect both services under certain technical siting constraints.

\section{Introduction}

The frequencies that are most widely used for communications. Satellites are presently used unidirectionally, $6 \mathrm{GHz}$ earth-to-space and $4 \mathrm{GHz}$ space-to-earth,: for example. Bi-directional use of the frequencies has been proposed as a means of increasing the orbit/spectrum resource available for space communications. This innovative use of the frequency spectrum has been discussed in the CCIR since $1978,1,2$. In February 1985, a paper by Pagones and Prabhu; ${ }^{3}$ showed that bi-directional frequency use by satellites would increase the interference experienced by $4 \mathrm{GHz}$ terrestrial systems. The paper presented here contributes further to the analysis. of the possibility of bi-directional use of frequencies for satellite communications.

The bi-directional use of frequencies allocated for space communications has the potential to double the orbit/spectrum capacity available. This paper examines the technical feasibility of reverse band use (RBU): at C-band (4. GHz uplinks and $6 \mathrm{GHz}$ downlinks). Figure. 1 shows satellites operating with both forward band use (FBU) and RBU. In order for bi-directional use to achieve a doubling of the orbit/spectrum capacity, RBU satellites will need to be interleaved among FBU satellites without causing significant interference to either system. With the FCC considering the implementation of a $2^{\circ}$ spacing plan for domestic C-band satellites, RBU satellites would need to be interleaved at $1^{\circ}$ separation, from FBU satellites. The analysis identifies the orbital separation requirements between RBU and FBU satellite systems. In addition, the constraints under which both forward and reverse band use satellite systems can share frequencies with terrestrial, line of sight transmission systems are examined.

Another interference path which would result from RBU implementation is interference between FBU and RBU earth stations. The analysis uses two approaches to determine coordination distances between earth stations based on (1) rain scatter transmission loss and (2) great circle path propagation. Interference from scatter paths is shortterm with statistics that are predicated on those of the scattering media (e.g., hydrometeors and aircraft). The great circle path analys is determines required losses for various path configurations (e.g., paths over water, paths in suburban areas, paths in urban areas) in different climate regions (e.g., continental temperature, maritime subtropic, equatorial, desert).

The final interference paths involve terrestrial radio relay stations with RBU systems. These paths include interference to terrestrial system receivers from both $\mathrm{RBU}$ earth station and satellite transmitters. There also exist interference paths from terrestrial transmitters into RBU earth stations and satellite receivers.

\section{Background}

\subsection{Sharing Criteria and Constraints:}

For Simultaneous FBU and RBU satellite systems directed to the same service area, the interference paths are as shown in Fig. 1. For acceptable operation, certain sharing criteria are required to be met. These are expressed in forms such as carrier-to-interference ratio (C/I), change in noise power due to interference $(\Delta T / T)$, and power flux density. (PFD) in a $4 \mathrm{kHz}$ bandwidth. Table 1 lists sharing criteria and constraints for RBU and FBU satellite systems. The criteria/constraints are the same for. RBU satellite systems as for FBU systems. The inter-system $C / I$ constraint is meant to indicate that. the interference level caused by the RBU downlink transmitter power at the FBU uplink receiver input is required to be $40 \mathrm{~dB}$ below the received carrier power, and vice versa. This indicates $10 \mathrm{~dB}$ better uplink $\mathrm{C} / \mathrm{I}$ performance due to this one interference source than the overall downlink performance of $30 \mathrm{~dB} \mathrm{C} / \mathrm{I}$. 
Since the interference paths shown in Fig. 1 are new and do not exist in the "situation now," any additional interference, $\Delta T$, or PFD affects the FBU system performance. Therefore, the system design task is to keep the effects on the existing systems as small as practicable without placing undue burdens upon the RBU satellite systems.

\subsection{Assumptions and Baseline Parameters}

It is envisioned that satellite systems operating in the reverse direction will carry similar types of signals as carried by forward direction systems. Therefore, it is reasonable to assume that levels of e.i.r.p. and transponder bandwidth will be similar. In an effort to minimize the cost of developing reverse band use it would be advantageous to utilize as much of the hardware developed for forward band use as possible.

A large area of developmental cost ${ }^{*}$ is associated with the earth station and satellite antenna systems. In conventional C-band systems the earth station antennas are often the same size for both transmit and receive applications. It is very reasonable to assume, therefore, that earth stations for RBU could utilize the same antennas used in FBU systems. For the satellite antenna systems many FBU satelites have equal gains at edge of coverage for the transmit and receive antennas. This requires that each antenna and/or the antenna feed network be sized for the appropriate frequency ( 4 or $6 \mathrm{~Hz}$ ). These same antennas could be used in the reverse direction so that edge of coverage gains are equal as well.

Since the antenna systems, e.i.r.p.'s, and transponder bandwidths are expected to be equivalent between FBU systems and RBU systems it is reasonable to assume that other parameters such as transmit powers, noise temperatures, power flux densities, etc. will also be equivalent. Link analyses using earth station and spacecraft parameters from typical current FBU C-band satellites show that no differences exist in end-to-end performance between. FBU systems and RBU systems under clear sky conditions. That is, the uplink and downl ink. carrier-to-noise ratio (C/N) values are equivalent for FBU and RBU systems. The RBU systems identified for these analyses are therefore assumed to be essentially the same, in size and performance as FBU systems.

Table 2 lists the baseline parameters used in the analyses of interference between satellite systems. These parameters were chosen as being representative of a typical C-band FBU satellite system such as the Hughes Galaxy or GTE Spacenet satellites. In addition parameters such as desired earth station e.i.r.p., interfering spacecraft e.i.r.p. and interfering spacecraft antenna half power beamwidth (HPBW) were varied over ranges of interest to demonstrate variations from the baseline system.

\subsection{Rain Attenuation Considerations}

With the assumptions made in Section 2.2, under clear sky conditions the end to end performance is the same for RBU and FBU. However, when propagation losses are present, performance characteristics differ between RBU and FBU due to differences in rain loss at 4 and $6 \mathrm{GHz}$. Figures $2(\mathrm{a})$ and (b) give rain attenuation levels for rain zones
$K$ and $P$ from CCIR Report 563-2. 4 Rain zone $K$ is a moderate rain zone covering much of the United States and Europe. Rain zone $P$ is a tropical rain zone having the greatest rainfall rates. Rain zone $\mathrm{K}$, for 0.01 percent of the worst month, $10^{\circ}$ elevation angle at $6 \mathrm{GHz}$ has $3.8 \mathrm{~dB}$ rain attenuation while at $4 \mathrm{GHz}$ there is $0.7 \mathrm{~dB}$ rain attenuation.

One way to analyze the effects of propagation is to calculate the maximum allowable receive system noise temperature necessary to achieve a given carrier-to-noise, $\mathrm{C} / \mathrm{N}$, ratio. The $\mathrm{C} / \mathrm{N}$ can be calculated as follows:

$C / N=E I R P_{T}+G_{R}(0)-L_{F S}-L_{A T}-10 \log (k T B)$
$C / N \quad$ carrier-to-noise ratio, dB
$E I R P_{T} \quad$ effective isotropic radiated power, dBW
$G_{R}(0) \quad$ on-axis receive antenna gain, dB
$L_{F S} \quad$ free space loss, dB
$L_{A T} \quad \begin{aligned} & \text { atmospheric loss, (including rain } \\ & k\end{aligned}$
Boltzmation) dB

$T$ receive system noise temperature, (includes receiver noise, sky noise, and atmospheric noise) $k$

B noise bandwidth, $\mathrm{MHz}$

Using parameters from Table 2 along with uplink and downlink $\mathrm{C} / \mathrm{N}$ values of 24 and $14 \mathrm{~dB}$, respectively, the maximum allowable system noise temperatures for 0.01 percent of worst month for CCIR rain zone $K$ at 10 elevation are listed below.

$\begin{array}{ccc} & \begin{array}{c}\text { Uplink } \\ (C / N=24 \mathrm{~dB})\end{array} & \begin{array}{c}\text { Downlink } \\ (\mathrm{C} / \mathrm{N}=14 \mathrm{~dB})\end{array} \\ \text { FBU. } & 432 \mathrm{~K} & 477 \mathrm{~K} \\ \text { RBU } & 887 \mathrm{~K} & 237 \mathrm{~K}\end{array}$

Typical values of system noise temperature are 800 to $1000 \mathrm{~K}$ for spacecraft receive systems and 150 to $200 \mathrm{~K}$ for earth station receive systems. This example shows that the $3 \mathrm{~dB}$ of additional. rain attenuation experienced on a $6 \mathrm{GHz}$ downlink compared to a $4 \mathrm{GHz}$ downlink may be compensated by a reduction in earth station receiver noise temperature. An easily achievable $237 \mathrm{~K}$ receiver system noise temperature is required to provide a $14 \mathrm{~dB} C / \mathrm{N}$ on RBU downlinks with $3.8 \mathrm{~dB}$ total rain attenuation.

The reduced rain attenuation on RBU uplinks at $4 \mathrm{GHz}$ compared to FBU uplinks at $6 \mathrm{GHz}$ has a potential advantage to RBU system design. However, in the analyses which follow, that advantage was not used.

For high rain rate areas, as in rain zone $P$, at tēnuation at $6^{-} \mathrm{GHz}$ for low evevation angles would cause too much channel degradation for satisfactory operation. RBU downlinks and FBU uplinks could likely not be used for 99.99 percent availability 
in these areas. However, rain zone $P$ is encountered primarily in the tropical regions where high elevation angles are possible and the resulting attenuation is less severe. Figure $2(b)$ shows that rain attenuation in zone $P$ for elevation angles greater than $30^{\circ}$ and 99.9 percent availability is approximately equal to the attenuation in rain zone $K$ for $10^{\circ}$ elevation and 99.99 percent availability.

\section{Satellite - Satellite Coordination/Separation}

The interference paths shown in Fig. 1 for FBU and RBU satellite systems require a certain minimum separation in orbit between FBU and RBU satellites and also impose orbital location constraints on widely separated satellites. These subjects are discussed in the following three sections.

\subsection{Interference Between Adjacent Satellites}

For FBU and RBU satellites using the same uplink and downlink frequencies, it is required that there be sufficient free space attenuation over the separation distance to reduce the interference to an acceptable level. It would be desirable for maximum orbit capacity to be able to interleave a system of RBU satellites within the existing FBU system. For a $2^{\circ}$ orbital spacing this would require placing RBU satellites a maximum of $1^{\circ}$ away from FBU satellites. In this case the interference between adjacent satellites operating in reverse directions must be well below the level of interference between adjacent satellites operating in the same direction. If this is possible, a doubling of the orbit capacity could be achieved by implementing RBU. For fixed satellite service FBU systems the minimum allowable.single entry co-channel $\mathrm{C} / \mathrm{I}$ level is about $35 \mathrm{~dB}$ with an allowable aggregate level $\left(\mathrm{C} / \mathrm{I}_{\mathrm{T}}\right)$ of about $30 \mathrm{~dB}$. In order that the interference from RBU satellites not significantly affect these limits, a single entry, co-channel $\mathrm{C} / \mathrm{I}$ level of about $45 \mathrm{~dB}$ between FBU and RBU satellites and an aggregate level of about $40 \mathrm{~dB}$ would be required. This would result in less than $0.5 \mathrm{~dB}$ increase in total interference because of RBU satellite systems.

In the analysis of satellite-satellite coordination, a cluster of like direction satellites interfering on a wanted satellite operating in the reverse direction was examined. Assuming clear sky conditions and baseline parameters from Table 2 the case of FBU satellites interfering on a RBU satellite represents the worst case condition. This is because earth station EIRP values are smaller for RBU at $4 \mathrm{GHz}$ uplink frequency.

Table 3 shows calculated C/IT values for a cluster of 10 interfering satellites operating in a direction opposite that of the wanted satelitite for a range of earth station EIRP values, spacecraft EIRP values, and half power beamwidths. Interfering satellites were spaced at $+1^{\circ},+3^{\circ}$, $+5^{\circ},+7^{\circ}$, and $+9^{\circ}$ apart from the wanted satellite as ilTustrated in Fig. 3. Interfering satellites spaced further than $+9^{\circ}$ were found to contribute negligibly to the total C/I. All satellites were considered to be serving the same coverage area. with an antenna half power beamwidth of $4^{\circ}$ by $8^{\circ}$ (except when HPBW was varied). This would provide an elliptical beam covering CONUS with an on-axis gain of $30 \mathrm{~dB}$ and edge of coverage gain of $26 \mathrm{~dB}$ (typical of current FBU systems). The ranges of EIRP chosen encompass values used with the vast majority of current C-band systems in orbit and planned for launch in the near term. The most common values range between 60 to $80 \mathrm{dBW}$ for earth station EIRP and 35 to $45 \mathrm{dBW}$ for spacecraft EIRP at center of coverage area. The range of HPBW was selected based on the following: (1) The largest rigid antenna deployable by either shuttle or Ariane is about $3.3 \mathrm{~m}$ diameter. This results in a $\mathrm{HPBW}$ of $1.07^{\circ}$ at $6 \mathrm{GHz}$ and $1.6^{\circ}$ at $4 \mathrm{GHz}$. (2) $\mathrm{A}$ $17.4^{\circ} \mathrm{HPBW}$ antenna provides global coverage.

The baseline parameter values for earth station EIRP of $70 \mathrm{dBW}$ for FBU and $66.5 \mathrm{dBW}$ for RBU result in total C/I values of 54.5 and $51.0 \mathrm{~dB}$, respectively when spacecraft EIRP is $38 \mathrm{dBW}$. Both of these levels are well above the aggregate $\mathrm{C} / \mathrm{I}$ value of $40 \mathrm{~dB}$ which was determined to be necessary so that the primary source of total interference is from adjacent satellites operating in the same direction as the wanted satellite. (Under the assumption that the feederlink is designed to contribute little to the overall downlink $\mathrm{C} / \mathrm{I}$, a requirement for cross system interference equal to within system interference on the feederlink is reasonable.) It is therefore seen that a system of RBU satellites could be interleaved with $2^{\circ}$ spaced FBU satellites and that frequency sharing between the satellites themselves should not present a problem. The data in Table 3 can be used to obtain information about deviations from the baseline parameters.

Figures 4 to 6 give the calculated $C / I$ ratios for two satellites operating in opposite directions as their orbital separation is varied from $0: 1^{\circ}$ to approximately $163^{\circ}$ (near antipodal). In each case the baseline parameters from Table 2 are used with the RBU satellite as the wanted system and the FBU satellite as the interferer (this again represents the worst case condition). In Fig. 4 the circular HPBW of the interfering satellite was varied between $1^{\circ}$ and $17^{\circ}$. Figure 5 indicates the effect of varying EIRP levels of the interfering satellite. The range of 30 to $50 \mathrm{dBW}$ is representative of typical C-band systems. Figure 6 shows the effect of varying the wanted system EIRP over 50 to $80 \mathrm{dBW}$. By interpolation between the curves in Fig. 5 it can be found that the minimum spacing necessary to achieve a single entry C/I value of $45 \mathrm{~dB}$ is approximately $0.33^{\circ}$. If station-keeping errors of $+0.1^{\circ}$ are allowed on each satellite, the minimum spācing allowable would be $0.53^{\circ}$ to account for simultaneous worst case station-keeping errors.

\subsection{Interference Between Near Antipodal Satellites}

The possibility of interference between near antipodal satellites exists when two satellites operating in reverse directions are on a line in the equatorial plane tangent to the earth's surface as in Fig. 7. The worst case situation occurs when both satellite's beams are pointed toward the horizon at the earth's equatorial limb. This occurs for a satellite geocentric angular separation of approximately $163^{\circ}$.

The analysis was performed using parameters from Table 2 and HPBW values ranging between $1^{\circ}$ to $17^{\circ}$ as shown in Table 4. Interfering spacecraft EIRP was held constant at $38 \mathrm{dBW}$. Beams were assumed to be pointed toward the equator with the $-3 \mathrm{~dB}$ contours of the wanted and interfering 
satellite beams touching at the horizon. Both satellites were assumed to have equal circular HPBW values. To indicate the drop in interference as satellite separation is reduced from the antipodal value at $163^{\circ}, \mathrm{C} / \mathrm{I}$ ratios were calculated for separations of $159^{\circ}$ to $163^{\circ}$ as shown in Table 4 . Clear sky conditions were assumed and no refractive effects were included.

For the antipodal spacing of $163^{\circ}$, calculated C/I values range from 40.62 to $41.83 \mathrm{~dB}$ for $\mathrm{HPBW}$ values $1^{\circ}$ to $17^{\circ}$, respectively. Because the $-3 \mathrm{~dB}$ contours were made to touch for all HPBW values the off-axis gains were equal to $-3 \mathrm{~dB}$. The variation in C/I over HPBW comes from the difference in slant range between a $1^{\circ}$ beam and a $17^{\circ}$ beam when $-3 \mathrm{~dB}$ contours are pointed at the horizon. [Note that if both wanted and interfering main beams were pointed at the horizon, $C / I$ levels would decrease by $6 \mathrm{~dB}$.]

Table 4 shows that for small reductions in orbital spacing from the antipodal position, rapid decreases in interference level were found for small HPBW systems. However, small reductions in orbital spacing provide only minor decreases in interference level for large HPBW systems. This would indicate that placing opposite direction satellites, both providing global coverage, at or near antipodal orbit locations should be avoided.

Rain attenuation can affect both the wanted feeder-link path and the interfering path from the antipodal satellite. In general, the interfering path will have a statistical likelihood of greater attenuation because of a greater path length through the atmosphere.

In surmary, for certain combinations of system parameters, particularly those having global beams, it may be necessary to avoid the nearly antipodal geometry. An alternate orbit location for either satellite would suffice.

\section{3. $\Delta T / T$ Coordination Criteria}

An alternate approach to examining the satellite-satellite sharing situation is calculation of $\Delta T / T$ instead of $C / I$. Appendix 29 of the Radio Regulations presents a method of calculation for determining if coordination is required between geostationary-satellite networks sharing the same frequency bands, i.e., $\Delta T / T$. In this method, the apparent increase in the equivalent satellite link noise temperature resulting from an interfering emission of a given system is calculated and the ratio of this increase to the equivalent satellite. link noise temperature, expressed as a percentage, is compared to a threshold value. Case II in Appendix 29 addresses sharing between FBU and RBU systems. The threshold value of $\Delta T / T$ for single entry interference is 4 percent. That is, if the calculated $\Delta T / T$ exceeds 4 percent, coordination between satellites is required.

The calculation of $\Delta T / T$ using the baseline parameters from Table 2 is presented in Table 5 for single entry interference between closely spaced satellites. The worst case is represented when interference is to the RBU system. The calculated value of 0.073 percent is well below the 4 percent threshold for coordination. The interfering spacecraft transmit power could be increased to as much as $-50 \mathrm{dBW} / \mathrm{Hz}$ (corresponding to a spacecraft EIRP of $55 \mathrm{dBW}$ over $36 \mathrm{MHz}$ ) and still be within the 4 percent threshold for coordination. If a uniform rectangular spectral distribution is assumed over the $36 \mathrm{MHz}$ channel, a spacecraft EIRP of $55 \mathrm{dBW}$ would exceed the power flux density limit of $-152 \mathrm{dBW}$ in a $4 \mathrm{kHz}$ band. Adjacent satellites operating in reverse directions can therefore be interleaved in a $2^{\circ}$ spacing plan with virtually no need for coordination.

Table 6 presents $\Delta T / T$ using the baseline parameters from Table 2 for single entry interference between near antipodal satellites. For interference to RBU systems $\Delta T / T$ is calculated to be 1.46 percent, again beneath the. 4 percent threshold for single entry interference. If the interfering spacecraft EIRP were increased to the level corresponding to the maximum allowable power flux density $(-152 \mathrm{dBW} / 4 \mathrm{kHz})$ the 4 percent threshold would be exceeded and coordination would be required. The systems could be brought within the threshold limit by increasing the uplink $\mathrm{C} / \mathrm{N}$ of the wanted system which would have the effect of lowering the wanted transmission gain to $-19.5 \mathrm{~dB}$.

\section{Interference and Coordination Between FBU and RBU Earth Stations}

For the interference paths shown in Fig. 1, separations are required between the sites of earth station transmitters and receivers in order to limit the interferences to acceptable levels. Coordination distances between RBU and FBU earth stations and practical site separations are discussed in this section of the paper. It is noted that only the earth station transmitter and receiver on opposite ends of an interference path shown in Fig. 1 are constrained in relative location. The locations of earth stations at $4 \mathrm{GHz}$ remains independent of the location of those at $6 \mathrm{GHz}$ and vice versa, even with both FBU and RBU satellite systems simultaneously serving the same service area. Thus, the siting constraints developed here apply only to terminals operating at the same frequency.

\subsection{Coordination Areas}

Procedures have already been developed for determining coordination areas for the case of transmitting and receiving earth stations operating in the same band. For example, in chronological order, the RARC-83 Final Acts (Part II, Article 7 and Annex 4), ${ }^{5}$ CCIR Doc. $4 / 133,6$ and IWP $5 / 2$ DOC. $84 / 16$ (1984).

The existing methods for determining the RBU/FBU coordination area are at an early stage of development. The most current version available for use in this analysis, IWP 5/2 Doc. 84/16, embodies more precise sharing parameter assumptions than earlier versions (e.g., RARC-83). Consequently, it results in smaller coordination distances without sacrificing their reliability. For transmissions over land, between FBU and RBU earth stations, the calculated coordination distances range from 210 to $340 \mathrm{~km}$ at $4 \mathrm{GHz}$ and 170 to $300 \mathrm{~km}$ at $6 \mathrm{GHz}$. These are the distances that would trigger coordination. Unacceptable interference will not necessarily exist with these site separations. 


\subsection{Actual Earth Station Satellite Siting Constraints}

The coordination distances of Section 4.1 are indicative of RBU/FBU earth station separation distances beyond which no interference could be expected. Upon more detailed analysis, much closer earth station separations would be shown to be acceptable under realistic circumstances. Site separation analyses were performed using great circle path propagation calculations and rain scatter path interference modeling. The great circle path attenuation calculations are dependent on path profile. Rain scatter is another mechanism by which energy from earth station emissions $c$ an be coupled into an earth station receiver. Coupling can occur through the main beam, sidelobes, and backlobes of the receiving earth station antenna.

\subsubsection{Great circle path propagation} mechanisms. Interfering signal power levels must be evaluated at the earth station receiver for at least two exceedance time percentages to ascertain conformity with long term and short term system performance objectives (see CCIR Report 448-3). The corresponding single entry interference criteria are assumed to be as follows (IWP $5 / 2$ Doc. 84/16):

$$
\begin{gathered}
\text { I }(20) \leq-174.6 \mathrm{dBW} / 25 \mathrm{kHz} \\
\text { I }(0.005) \leq-163.9 \mathrm{dBW} / 25 \mathrm{kHz}
\end{gathered}
$$

where $I(p)$ is the interfering power level, at the receiving antenna output, which is not be exceeded for more than $p$ percent of the time. It should be noted that these are based on coordination criteria and their use as acceptable interference criteria consequently leads to more severe siting constraints than would be needed in practice.

For near-median time percentages (e.g., 20 percent), the determinative great circle path propagation mechanisms include multipath, refraction, and several kinds of diffraction, which often lead to basic transmission losses that substantially differ from free space loss. In some cases; troposcatter or ducting may predominate. For short-term time percentages (e.g., 0.005 percent), the determinative great circle path propagation mechanisms are typically ducting or troposcatter and diffraction. The climate and terrain both have a radical effect on basic transmission loss; accordingly, several climate types and great circle path terrain configurations have been selected for analysis of RBU/FBU earth station sharing. An integrated multiple-mode propagation analys is computer program was used which embodies the empirical propagation models of the United States National Bureau of Standards TN-101 (rev. 1971), (see also CCIR Reports 238-4 and 569-2).

The assumed paths between RBU and FBU earth stations and the associated radiometeorological climates represent a broad range of conditions with moderate separation distances that could be expected with RBU implementation; however, no consideration is given to site shielding. While the propagation analysis computer program is useable with close-in site shielding, it is desirable to first consider this sharing without regard to that factor. The propagation analysis program was used to calculate the resulting basic transmission losses. The use of basic transmission loss in the analysis, as opposed to transmission loss, eliminates the sometimes significant loss factor of aperture-to-medium coupling loss. This simplification would result in an insignificant under estimation of loss because of the low mutual antenna gains involved.

The predicted basic transmission losses $L(p)$, which are exceeded for at least p percent of the time, can be used with the following equation to determine the associated siting constraints:

$$
\begin{aligned}
{\left[L(p)+I(p)-P_{t}\right] \geq G_{t}\left(\theta_{1}\left(\alpha_{1}\right)\right) } & \\
& +G_{r}\left(\theta_{2}\left(\alpha_{2}\right)\right)-A_{s}-F D R
\end{aligned}
$$

where:

I(p) the interfering power level, at the receiving antenna output, which is not to be exceeded for more than $p$ percent of the time $(\mathrm{dBW})$.

$\mathrm{P}_{\mathrm{t}} \quad$ The transmit power level, in a reference bandwidth ( $\mathrm{dBW}$ )

$G_{t}\left(\theta_{1}\left(\alpha_{1}\right)\right)$ The transmitting earth station (FBU or RBU) antenna gain towards the receiving earth station $(\mathrm{dB} i)$;

$G_{r}\left(\theta_{2}\left(\alpha_{2}\right)\right)$ The receiving earth station (FBU or RBU) antenna gain toward the transmitting earth station ( $d B i)$;

$\theta_{x}\left(a_{x}\right) \quad$ The earth station antenna off-axis angle $\theta$ in the azimuth $\alpha$, as used with $G_{t}$ and $G_{r}$;

$A_{S} \quad$ The combined earth stations' site shielding losses $(A B)$, resulting from berms, screens, or other earth station placements made to enhance electromagnetic compatibility;

FDR

\section{The frequency dependent rejection} (dB) resulting from consideration of frequency plans.

In the minority of cases where earth station antenna discriminations alone do not assure compatibility, the site shielding losses and/or frequency plans must be considered. The conservative site shielding loss analysis methods of CCIR Reports 831 (screens), 390-4 (obstacle shielding), and 709-1 (coupling factor) can be used. Individually, these factors can provide shielding losses well upwards of $10 \mathrm{~dB}$. For example, a $25 \mathrm{~dB}$ reduction in received interference power has been reported for a berm around a 10 meter earth station antenna (Report 390-4).

CCIR Reports 654 and 388-4 present methods for evaluating the FDR. The frequency plans used by FBU and RBU earth stations could be expected to provide high inter-system isolation without adjustment to frequency plans because it is unlikely that co-channel operation would occur. In the event that additional FDR might be required, the planned and/or existing networks frequency plans could be adjusted to better take advantage of receiver selectivity. FORs in the 90 to $100 \mathrm{~dB}$ 
range can often be achieved before receiver frontend saturation effects would become a problem.

The results of the analysis show separation distances of 10 to $100 \mathrm{~km}$ are sufficient between earth stations to assure compatibility. The exact distances are dependent on terrain and climatic region. Practical site separations where mutual site shielding, barriers, and other techniques are used are expected to range from 10 to $40 \mathrm{~km}$.

4.2.2. Interference propagation via scatter paths. The FBU and RBU earth station mutual antenna discriminations greatly facilitate sharing when interfering signal propagation over great circle paths is considered. However, as with earth station/terrestrial station sharing, significant interfering signa! propagation can occur over nongreat-circle scatter paths where those antenna discriminations cannot be fully realized. The interference from scatter paths is short-term with statistics that are predicated on those of the scattering media. Hydrometeors and aircraft are the scattering media of concern in RBU/FBU earth station sharing, it being assumed that scatter from automobiles is of no concern because of the elevated antenna mainbeams.

The analysis uses the procedures presented in CCIR Report 569-2. It is assumed that a rain cell is in the near field of a transmitting earth station operating at a given elevation angle. The distance between the transmitting earth station antenna and the edge of the idealized rain cell is typically less than 1 to $2 \mathrm{~km}$. The interfered with, or victim receiving earth station is located a distance of 10 to $100 \mathrm{~km}$ from the center of the rain cell for the analyses.

For operating frequencies below $10 \mathrm{GHz}$, Rayleigh scattering by the hydrometeors at iine of sight altitudes to the victim earth station is the predominate mechanism. The scattered signal may enter the victim earth station antenna through any of the line of sight antenna lobes.

Rain scatter transmission loss was evaluated for the set of conditions given in Table 7. The maximum rain scatter transmission loss occurs for forward scatter: the coupling is into the backlobe of the victim earth station antenna. Conversely, the minimum rain scatter transmission loss occurs for back scatter: coupling is through a relatively small angle off boresight of the victim earth station antenna. A polar plot showing the rain scatter transmission loss variation as a function of the bistatic scattering angle is given in Fig. 8 for a $3 \mathrm{~m}$ diameter victim earth station antenna. As shown in the figure, the rain scatter transmission loss is smallest when the bistatic angle is within about $+65^{\circ}$ from the back scatter value of $180^{\circ}$.

For a $3 \mathrm{~m}$ earth station operating at a $3^{\circ}$ elevation angle the criteria is met for forward scatter geometries at rain rates up to $13.5 \mathrm{~mm} / \mathrm{hr}$ and for separation distances of $10 \mathrm{~km}$ or more. For a rain rate of $80.5 \mathrm{~mm} / \mathrm{hr}$, a minimum separation distance of about $40 \mathrm{~km}$ is required, escalating to about $100 \mathrm{~km}$ for a rain rate of $178 \mathrm{~mm} / \mathrm{hr}$.. - For back scatter geometry, the rain scatter transmission loss is less than the required value in all cases. The same basic conclusions apply to victim earth stations using antennas of 7 and $10 \mathrm{~m}$ in diameter.

From the results of this preliminary analysis, it is concluded that reverse band use by earth stations, operating in different networks is feas $i$ ble from the viewpoint of interference due to rain scatter coupling in a common volume. The successful application of reverse band use requires that the earth stations be sited such that rain scatter coupling between the earth stations be, to the extent possible, through the far sidelobes. Back scatter geometries are to be avoided.

\section{Analysis of Terrestrial System and RBU}

The interference paths for this frequency sharing situation are shown in Fig. 9. Each and every type of transmitter causes interference to one and only one type of receiver, and all receivers are subject to interference. The situation is completely analogous to the interaction between FBU satellite systems and terrestrial systems. The interferences shown in Fig. 9 with RBU satellite systems are new interferences, but because of the similarity to FBU systems, the solutions are of the same type. Siting constraints, PFD limits, and other previously used techniques can be used to limit the interferences produced.

\subsection{Effects of Terrestrial Systems on RBU Satellite Systems}

To limit the interfering effects of terrestrial transmitters it is proposed to constrain the terrestrial system as listed below.

Constraints on Terrestrial Systems to Limit Interference to RBU Satellite Systems

\section{Constraint}

Value

EIRP (Terrestrial Transmitter)

I/N (Terrestrial Trans. into RBU E/S)

Terr. Trans. Pointing Away from GSO $-12.5 \mathrm{~dB} *$

* I/N to be exceeded no more than 20 percent of the time

These constraints are of the same type and at the same level as constraints imposed to protect the FSS in the forward band.

Protection of earth station receivers at $6 \mathrm{GHz}$ would require coordination with and separation from terrestrial system $6 \mathrm{GHz}$ transmitters. Analysis shows that the coordination distances and the practical site separations are similar to the case of $4 \mathrm{GHz}$ FBU receivers. These problems have been shown to be solvable by the demonstrated ability to locate a large number of $4 \mathrm{GHz}$ receive terminals in the midst of a very dense $4 \mathrm{GHz}$ terrestrial radio relay network in the United States.

The $4 \mathrm{GHz}$ RBU spacecraft receivers are impacted by the $4 \mathrm{GHz}$ terrestrial radio relay transmitters. To_control_ this _potential__source_of_interference, the terrestrial transmitters would need to be constrained in EIRP and required to point away from the geostationary orbit. These constraints would also be similar to what is now done at $6 \mathrm{GHz}$ in 
the FBU situation. Analysis shows that the terrestrial system interference into RBU satellite systems is about $3 \mathrm{~dB}$ greater than for FBU systems, for a given terrestrial transmitter density. In cases of high transmitter density, this may cause the FSS system noise budget for out-ofsystem interference to be exceeded. The RBU satellite systems in these cases could accept the additional interference with no penalty, as long as the total noise budget is not exceeded.

\subsection{Effects of RBU Satellite Systems on Terrestrial Systems}

To limit the interfering effects of RBU sate?lite system transmitters, it is proposed to constrain the operation as given below.

Constraints on RBU Satellite Systems to Limit Interference to Terrestrial systems

\section{Constraints}

$\underline{\text { Value }}$

Sat. PFD vs Angle of Arrival

$-152 \mathrm{dBW} / \mathrm{m}^{2} / 4$ $\mathrm{KHz}^{\star}$

I/N (RBU E/S into Terr. Rcvr.) $16 \mathrm{~dB}^{* *}$

* Increasing to $-142 \mathrm{dBW} / \mathrm{m}^{2}$

$\star \star I / N$ to be exceeded no more than $20 \%$ of time

These constraints are the same in type and level as those under which FBU satellite systems now operate.

The analysis was performed for interference to terrestrial receivers from a constellation of 48 satellites at $2^{\circ}$ spacing. The PFD from each satellite was calculated assuming only free space loss and a transponder output power of $10 \mathrm{~W}$. For terrestrial stations located over a range of latitudes and relative elevation angles the total interference power received was well within the limit of $-152 \mathrm{dBW} / \mathrm{m}^{2} / 4 \mathrm{kHz}$ as specified by the PFD limit on current FBU satellites.

Terrestrial system receivers at $6 \mathrm{GHz}$ will be impacted by RBU satellite transmitters. To minimize this impact, terrestrial system receivers at $6 \mathrm{GHz}$ could be required to avoid pointing at the geostationary orbit by $+2^{\circ}$, as is currently required for $4 \mathrm{GHz}$ terréstrial system receivers. The residual interference into $6 \mathrm{GHz}$ terrestrial receivers could be accommodated by a reapportionment of the interference allotted to satellite systems or by a restructuring of the total interference budget.

At $4 \mathrm{GHz}$, the satellite system earth station transmitters have potential for interference to terrestrial system $4 \mathrm{GHz}$ receivers. Coordination procedures and site separation as are now used at $6 \mathrm{GHz}$ for FBU would be necessary to keep the interference acceptably low. And of course, some allowance must be made in the total interference budget to accommodate this new interference source.

\subsection{Sharing Between RBU Earth Stations and Terrestrial Stations}

Frequency sharing, regulatory management, administrative, and technical problems between terrestrial stations and RBU earth. stations are no different from those of FBU earth stations. The coordination process is already established and the mutual terrestrial station/earth station siting constraints are well understood. For example, the considerations for coordination distances would be as follows.

- For receiving RBU earth stations, coordination distances with respect to terrestrial transmitters are less than those for receiving FBU earth stations. This is because the interference is propagated at $6 \mathrm{GHz}$ in the RBU case, as opposed to $4 \mathrm{GHz}$ in the FBU case.

- For transmitting RBU earth stations, coordination distances with respect to terrestrial receivers are greater than those for transmitting FBU earth stations. This is because the interference is propagated at $4 \mathrm{GHz}$ in the RBU case, as opposed to $6 \mathrm{GHz}$ in the FBU case.

It would appear that the introduction of $\mathrm{RBU}$ would compound the present overall siting constraints for terrestrial stations. However, this is not in fact the case. Section 4 shows that there are some constraints on siting between FBU and RBU earth stations. While these are only modest constraints, they do tend to limit the overall density of RBU and FBU earth stations in the vicinity of any given current or planned terrestrial station site. For example, if there are several FBU transmitting earth stations near a planned terrestrial station route, it is most unlikely that there could also be several proximate receiving RBU earth stations (RBU and FBU earth stations operating in the same band). As a result, terrestrial receivers planned for the same band would be subject to siting constraints from the FBU earth stations, but the associated terrestrial transmitters would not be significantly constrained by the RBU implementation.

\section{Conclusions}

This paper presents the results of an analys is of the technical feasibility of bi-directional use of frequencies for satellite communications. Determinations were made of the RBU system size, intra- and inter-system constraints, and the criteria for sharing with terrestrial systems.

The analytic approach included using existing computer models, developing new models, performing link calculations, and determining propagation losses, coordination distances, and power flux densities. The results of the analysis showed that RBU satellite systems are similarly sized to FBU satellite systems. RBU is technically feasible, however both satellite and terrestrial systems are subject to certain technical constraints.

The analysis showed that a carrier to interference ratio of $45 \mathrm{~dB}$ can be maintained between RBU and FBU satellites separated by less than $0.5^{\circ}$, and that a carrier to interference ratio of $42 \mathrm{~dB}$ can be maintained in the antipodal case. Rain scatter propagation analysis showed that RBU and FBU earth stations require separation distances of less than $10 \mathrm{~km}$ at a rain rate of $13.5 \mathrm{~mm} / \mathrm{hr}$ escalating to less than $100 \mathrm{~km}$ at a rain rate of $178 \mathrm{~mm} / \mathrm{hr}$ for earth station antennas in the 3 to $10 \mathrm{~m}$ range. The analysis also showed that the present interference limits for stations in the 
fixed service sharing allocations with the FSS are adequate to protect both services under certain technical siting constraints.

\section{References}

1. "The Use of Frequency Bands Allocated to the Fixed-Satellite Service for Both the Up link and Down link of Geostationary-Satellite Systems," CCIR Report 557-1, CCIR XV Plenary Assembly, Vol. IV Part 1, International Telecommunication Union, Geneva, Switzerland, 1982, pp. 361-369.

2. "Technical Factors Influencing the Efficiency of Use of the Geostationary-Satellite Orbit by Radio Communication Satellites Sharing the Same Frequency Bands. General Summary, "CCIR Report 453-3, CCIR XV Plenary Assembly, Vol. IV Part 1, International Telecommunication Union, Geneva, Switzerland, 1982, pp. 272-306.

3. Pagones, M.J. and Prabhu, V.K., "Effect of Interference from Geostationary Satellites on the Terrestrial Radio Network - A Case Study with Bi-Directional Transmission," AT\&T Bell Laboratories, Holmdel, NJ, 1985.
4. "Radiometeorological data," CCIR Report 563-2, CCIR XV Plenary Assembly, Vol. V, International Telecommunication Union, Geneva, Switzerland, 1982, pp. 96-123.

5. "Final Acts of the Regional Administrative Radio Conference for the Planning of the Broadcasting Satellite Service in Region 2 (SAT-83)," International Telecommunication Union, Geneva, Switzerland, 1983.

6. "Determination of the Bi-Directional Coordination Area," Draft New Report Approved at CCIR Interim Meetings of Study Group 4, CCIR $4 / 133$ Rev. 1., (CCIR 9/155 Rev. 1), International Telecommunication Union, Geneva, Switzerland, May 1984.

7. Weiss; H., "Determination of the Bi-Directional Coordination Contour," Document $84 / 16$, CCIR IWP $5 / 2$, International Telecommunication Union, Geneva, Switzerland, April 1984. 
TABLE 1. - SHARING CRITERIA/CONSTRAINTS FOR RBU SATELLITE SYSTEMS

\begin{tabular}{|l|c|c|}
\hline \multicolumn{1}{|c|}{ Sharing criteria/constraints } & $\begin{array}{c}\text { Existing } \\
\text { FBU }\end{array}$ & $\begin{array}{c}\text { Required } \\
\text { RBU }\end{array}$ \\
\hline Aggregate co-channel C/I (intra-system) & $30 \mathrm{~dB}$ & $30 \mathrm{~dB}$. \\
Aggregate co-channel C/I (inter-system) & $40 \mathrm{~dB}$ & $40 \mathrm{~dB}$ \\
$\Delta T / T$ (interference between sats.) & 4 percent & 4 percent \\
$\Delta T / T$ (interference between E/S) & 5 percent & 5 percent \\
I/N (E/S transmitter into terr $)$ & $\mathrm{a} 16 \mathrm{~dB}$ & $\mathrm{a} 16 \mathrm{~dB}$ \\
$\mathrm{I} / \mathrm{N}$ (terr. transmitter into E/S) & $\mathrm{a}-12.5 \mathrm{~dB}$ & $\mathrm{a}-12.5 \mathrm{~dB}$ \\
PFD (in a $4 \mathrm{kHz}$ bandwidth) & $-152 \mathrm{dBW} / \mathrm{m}^{2}$ & $-152 \mathrm{dBW} / \mathrm{m}^{2}$ \\
& $($ increasing to & $($ increasing to \\
& $\left.-142 \mathrm{dBW} / \mathrm{m}^{2}\right)$ & $\left.-142 \mathrm{dBW} / \mathrm{m}^{2}\right)$ \\
\hline
\end{tabular}

To be exceeded no more than 20 percent of the time.

TABLE 2. - bASELINE PARAMETERS FOR INTERFERENCE ANALYSES BETWEEN SATELLITE SYSTEMS

\begin{tabular}{|c|c|c|}
\hline Earth station parameters & FBU & RBU \\
\hline $\begin{array}{l}\text { Antenna diameter, m } \\
\text { EIRP (dBW) on-axis } \\
\text { E/S } G / T, d B / K \\
\text { Te, } K \\
G \text { on-axis, } d B \text {. Transmit } \\
\quad(n=0.65) \text { Receive } \\
\text { Transmit power, dBW } \\
\text { Transmit, power, } W \\
\text { Feed loss, dB } \\
\text { Satellite parameters }\end{array}$ & $\begin{array}{r}10 \\
70 \\
28.1 \\
180 \\
54.1 \\
50.6 \\
16.9 \\
48.8\end{array}$ & $\begin{array}{r}10 \\
66.5 \\
31.6 \\
180 \\
50.6 \\
54.1 \\
16.9 \\
48.8 \\
1\end{array}$ \\
\hline $\begin{array}{l}\text { EIRP (dBW) edge of cov., }(-4 \mathrm{~dB}) \\
\text { Number transponders } \\
\text { Transponder } B W, M H z \\
\text { Te, } K \\
S / C \text { G } / T, d B / K \\
G \text { on-axis, dB } \\
G \text { edge of cov. }(-4 \mathrm{~dB}) \\
\text { Transmit power, dBW } \\
\text { Transmit power, W } \\
\text { Feed loss, } d B\end{array}$ & $\begin{array}{r}34 \\
12 \text { to } 24 \\
36 \\
1000^{\circ} \\
-4 \\
30 \\
26 \\
9.3 \\
8.5 \\
1.3\end{array}$ & $\begin{array}{r}34 \\
12 \text { to } 24 \\
36 \\
1000^{\circ} \\
-4 \\
30 \\
26 \\
9.3 \\
8.5 \\
1.3\end{array}$ \\
\hline
\end{tabular}

aTransmit powers are total power levels over the full transponder bandwidth. 
TABLE 3. - ADJACENT SATELLITE INTERFERENCE:

TEN INTERFERERS SPACED $\pm 1, \pm 3, \pm 5, \pm 7$, $+9^{\circ}$ FROM WANTED SATELLITE, ALL BEAMS

SERVING SAME COVERAGE AREA

\begin{tabular}{|l|l|l|l|}
\hline \multicolumn{1}{|c|}{$\begin{array}{c}\text { Parameter } \\
\text { (a) }\end{array}$} & $\begin{array}{c}\text { Level } \\
\text { (b) }\end{array}$ & C/IT & Comments \\
\hline E/S EIRP, & 50 & 34.5 & $4^{\circ}$ by $8^{\circ}$ Beams \\
dBW & 60 & 44.5 & \\
& $\frac{66.5}{70}$ & 51 & 54.5 \\
& $\frac{80}{60}$ & 64.5 & \\
& 90 & 74.5 & \\
On-axis & 30 & 59 & $4^{\circ}$ by $8^{\circ}$ Beams \\
S/C EIRP, & 35 & 54 & \\
dBW & 38 & 51 & \\
& 40 & 49 & \\
& 45 & 44 & \\
& 50 & 39 & \\
HPBW, deg & 1 & 81.1 & S/C EIRP \\
(for both & 3 & 62 & Fixed at \\
wanted and & 5 & 53.1 & 38 dBW. \\
interfering) & 7 & 47.3 & \\
& 9 & 42.9 & \\
& 11 & 39.4 & \\
& 13 & 36.5 & \\
& 15 & 34 & \\
& 17 & 31.9 & \\
\hline
\end{tabular}

$a_{A} 11$ other parameters should be taken from the baseline parameters in Table 2.

bunderlined values correspond to baseline conditions.

TABLE 4. - CALCULATED CARRIER-T0-INTERFERENCE RATIOS FOR NEAR-ANTIPODALLY SPACED FBU-RBU SATELLIIES. FBU INTERFERENCE INTO RBU. ANTENNA HPBW EQUAL FOR BOTH WANTED AND

INTERFERING SYSTEMS

\begin{tabular}{|c|c|c|c|c|c|}
\hline \multirow{2}{*}{ HPBW } & \multicolumn{5}{|c|}{ FBU-RBU sateliite separation. } \\
\cline { 2 - 6 } & 163.0 & 162.0 & 161.0 & 160.0 & 159.0 \\
\hline 1 & 40.62 & 58.60 & 74.59 & 74.58 & 74.56 \\
2 & 40.72 & 48.21 & 58.70 & 72.19 & 74.67 \\
3 & 40.83 & 45.49 & 51.48 & 58.80 & 67.45 \\
4 & 40.94 & 44.31 & 48.42 & 53.28 & 58.89 \\
5 & 41.05 & 43.68 & 46.78 & 50.37 & 54.44 \\
6 & 41.15 & 43.31 & 45.79 & 48.61 & 51.77 \\
7 & 41.25 & 43.08 & 45.15 & 47.46 & 50.02 \\
8 & 41.35 & 42.93 & 44.70 & 46.65 & 48.80 \\
9 & 41.44 & 42.83 & 44.37 & 46.07 & 47.90 \\
10 & 41.52 & 42.77 & 44.13 & 45.62 & 47.23 \\
11 & 41.59 & 42.72 & 43.95 & 45.27 & 46.70 \\
12 & 41.66 & 42.69 & 43.80 & 45.00 & 46.27 \\
13 & 41.71 & 42.66 & 43.68 & 44.77 & 45.92 \\
14 & 41.76 & 42.63 & 43.57 & 44.57 & 45.63 \\
15 & 41.79 & 42.61 & 43.48 & 44.40 & 45.37 \\
16 & 41.82 & 42.58 & 43.39 & 44.24 & 45.14 \\
17 & 41.83 & 42.54 & 43.30 & 44.09 & 44.93 \\
\hline
\end{tabular}


TABLE 5. - $\triangle T / T$ FOR SINGLE ENTRY INTERFERENCE USING BASELINE PARAMETERS (ADJACENT)

\begin{tabular}{|l|r|r|}
\hline \multicolumn{1}{|c|}{ Interference to } & \multicolumn{1}{|c|}{ FBU } & \multicolumn{1}{|c|}{ RBU } \\
\hline Relative satellite separation, deg & 1 & 1 \\
Receive frequency, GHz & 6 & 4 \\
Interferer transmit power, dBW/Hz & -67.6 & -67.6 \\
Interferer transmit gain, dBi & 0 & 0 \\
Free space loss between satellites, dB & 165.4 & 161.9 \\
Wanted receive gain, dBi & 0 & 0 \\
Wanted transmissior, gain, $r, \mathrm{~dB}$ & -7.9 & -7.9 \\
Wanted link noise temperature, $\mathrm{K}$ & 180 & 180 \\
$\Delta T / T$, percent & 0.033 & 0.073 \\
\hline
\end{tabular}

TABLE 6. - $\triangle T / T$ FOR SINGLE ENTRY INTERFERENCE USING BASELINE PARAMETERS (NEAR-ANTIPODAL)

\begin{tabular}{|c|c|c|}
\hline Interference to & FBU & RBU \\
\hline $\begin{array}{l}\text { Relative satellite separation, deg } \\
\text { Receive frequency, GHz } \\
\text { Interferer transmit power, } \mathrm{dBW} / \mathrm{Hz} \\
\text { Interferer transmit gain, } \mathrm{dB} i \\
\text { Free space loss between satellites, } \mathrm{dB} \\
\text { Wanted receive gain, } \mathrm{dBi} \\
\text { Wanted transmission gain, } \mathrm{r}, \mathrm{dB} \\
\text { Wanted link noise temperature, } \mathrm{K} \\
\text { On-axis gain, } \mathrm{G}_{m}, \mathrm{~dB} \\
\Delta T / T \text {, percent }\end{array}$ & $\begin{array}{r}163 \\
6 \\
-67.6 \\
\mathrm{Gm}_{2}-3 \\
206.5 \\
\mathrm{G}_{\mathrm{m}}-3 \\
-7.9 \\
180 \\
30 \\
0.64\end{array}$ & $\begin{array}{r}163 \\
4 \\
-67.6 \\
G m-3 \\
202.9 \\
G_{m}-3 \\
-7.9 \\
180 \\
30 \\
1.46\end{array}$ \\
\hline
\end{tabular}

TABLE 7. - CONDITIONS FOR WHICH RAIN SCATTER TRANSMISSION LOSS HAS BEEN EVALUATED

\begin{tabular}{|c|c|c|}
\hline $\begin{array}{l}\text { - Operating frequency, } \\
\text { - Elevation angle of interfering earth } \\
\text { station antenna, } \\
\text { - Elevation angle of victim earth station } \\
\text { antenna, } \\
\text { - Victim earth station antenna diameter, } \\
\text { - Distance to the rain cell, } \\
\text { - Rain rate } \\
\text { - Heights of the } 0{ }^{\circ} \mathrm{C} \text { isotherm } \\
\text { - Bistatic azimuth angle }\end{array}$ & $\begin{array}{r}f(\mathrm{GHz}) \\
\Phi_{S}(\mathrm{deg}) \\
\varepsilon_{1}(\mathrm{deg}) \\
\varepsilon_{2}(\mathrm{deg}) \\
D(\operatorname{meters}) \\
r+d c / 2(\mathrm{~km}) \\
R(\mathrm{~mm} / \mathrm{hr}) \\
h_{r} \cdot(\mathrm{km}) \\
\alpha_{T}(\mathrm{deg})\end{array}$ & $\begin{array}{r}4 \\
5 \\
25 \\
3,10 \\
3,7,10 \\
10,40,100 \\
13.5,80.5 \\
178,1 \\
5.2(2) \\
0-360 \text { in } \\
\text { steps of } 5\end{array}$ \\
\hline
\end{tabular}

Notes:

1. Corresponds to rain rates exceeded for 0.005 percent of the year for rain climates $A, 03$, and $H$, respectively.

2. Corresponds to the height exceeded 0.005 percent of the year at a latitude of 5 degrees. 

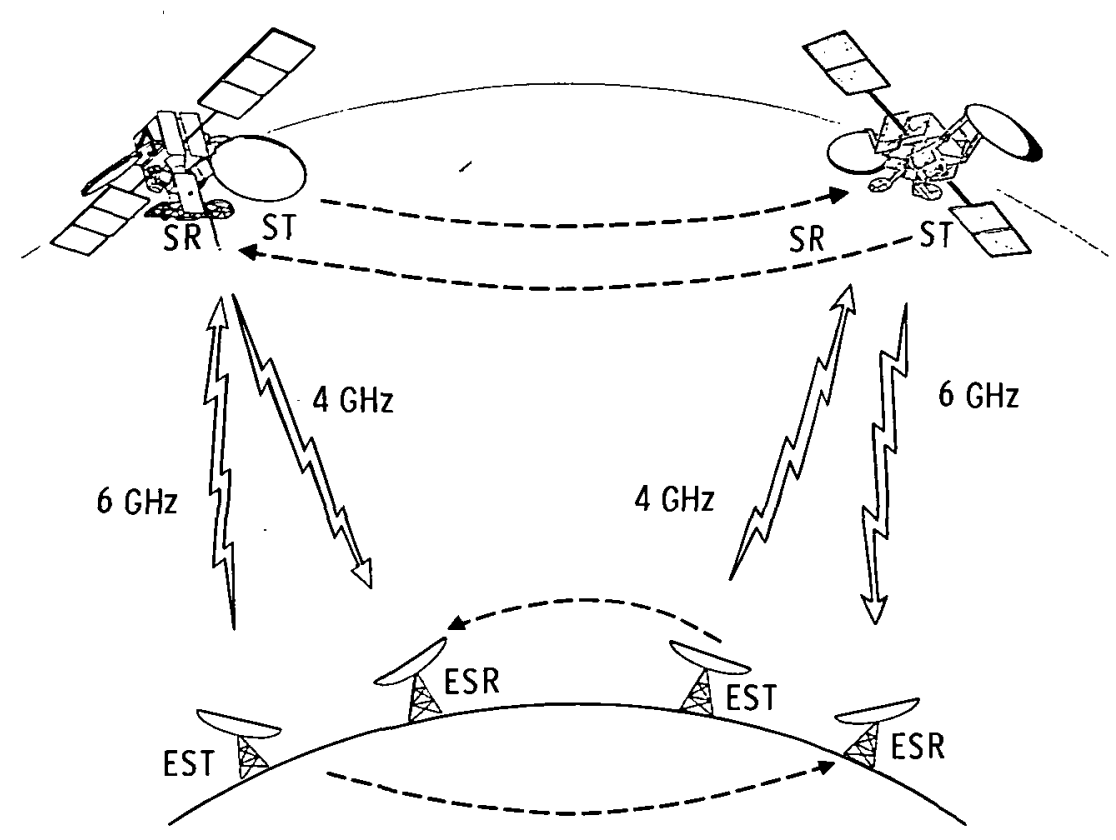

Figure 1. - FBU and RBU satellite systems.

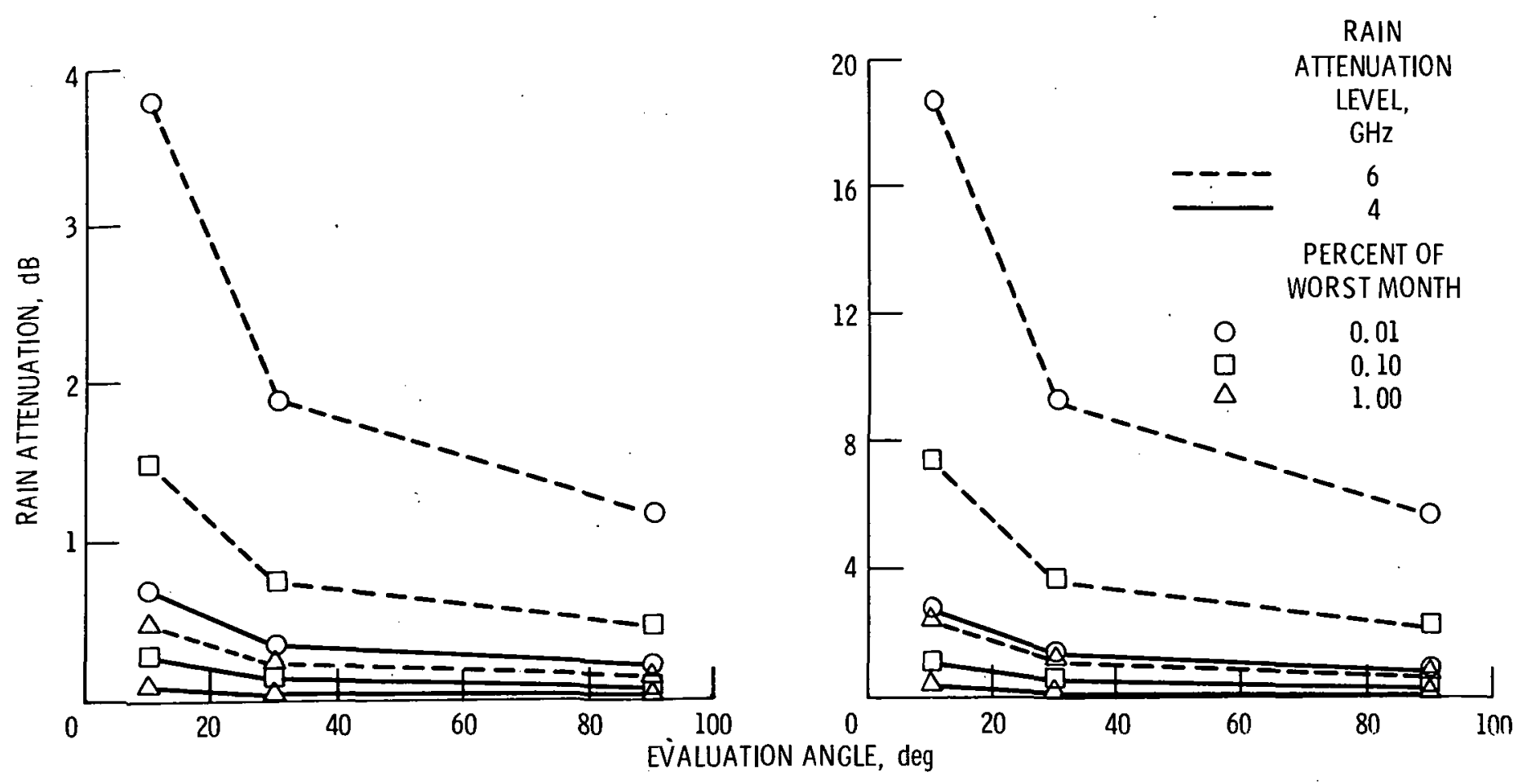

(a) Rain zone K.

(b) Rain zone $P$.

Figure 2. $-4 \mathrm{GHz}$ and $6 \mathrm{GHz}$ rain attenuation levels versus elevation angle for CCIR rain zones $K$ and $P$. 


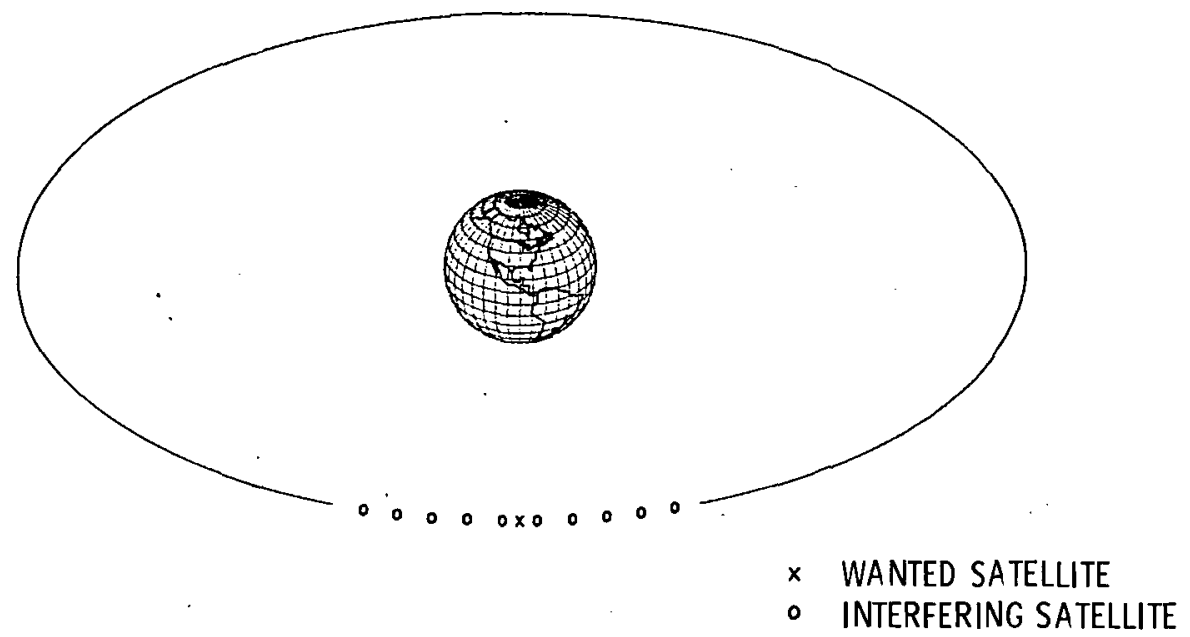

-Figure 3. - Adjacent satellite interference. Interferers at $\pm 1, \pm 3, \pm 5, \pm 7, \pm 9$ degrees from wanted satellite: 


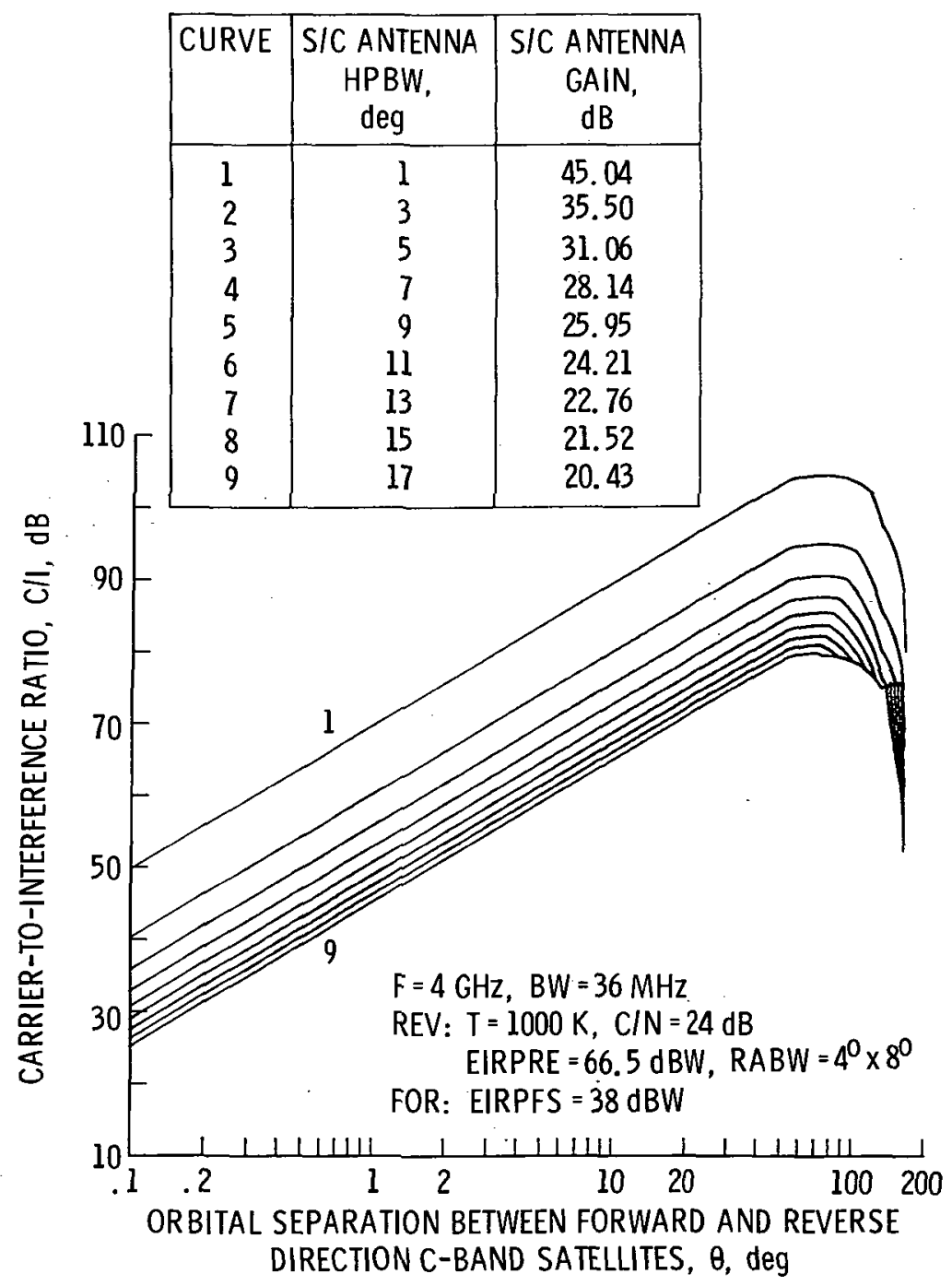

Figure 4. - RBU feeder-link $\mathrm{Cll}$ versus $\theta$ dependence on antenna HPBW of FBU satellite, EIRPRE = RBU E/S EIRP, EIRPFS $=F B U S / C E I R P, R A B W=R B U$ antenna HPBW. 


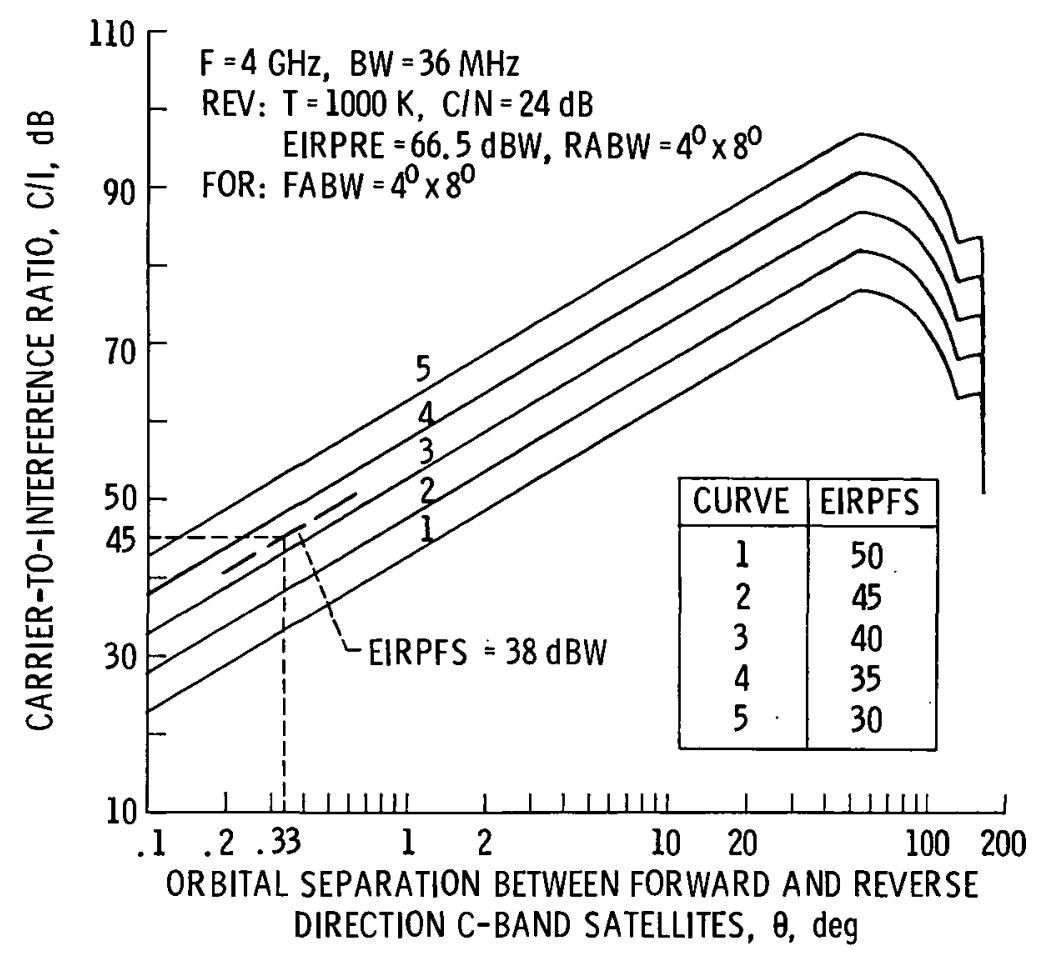

Figure 5. - RBU feeder-link Cll versus $\theta$ dependence on FBU S/C EIRP, EIRPRE $=$ RBU E/S EIRP, EIRPFS $=F B U$ $S / C$ EIRP, RABW = RBU antenna HPBW, FABW $=F B U$ antenna HPBW.

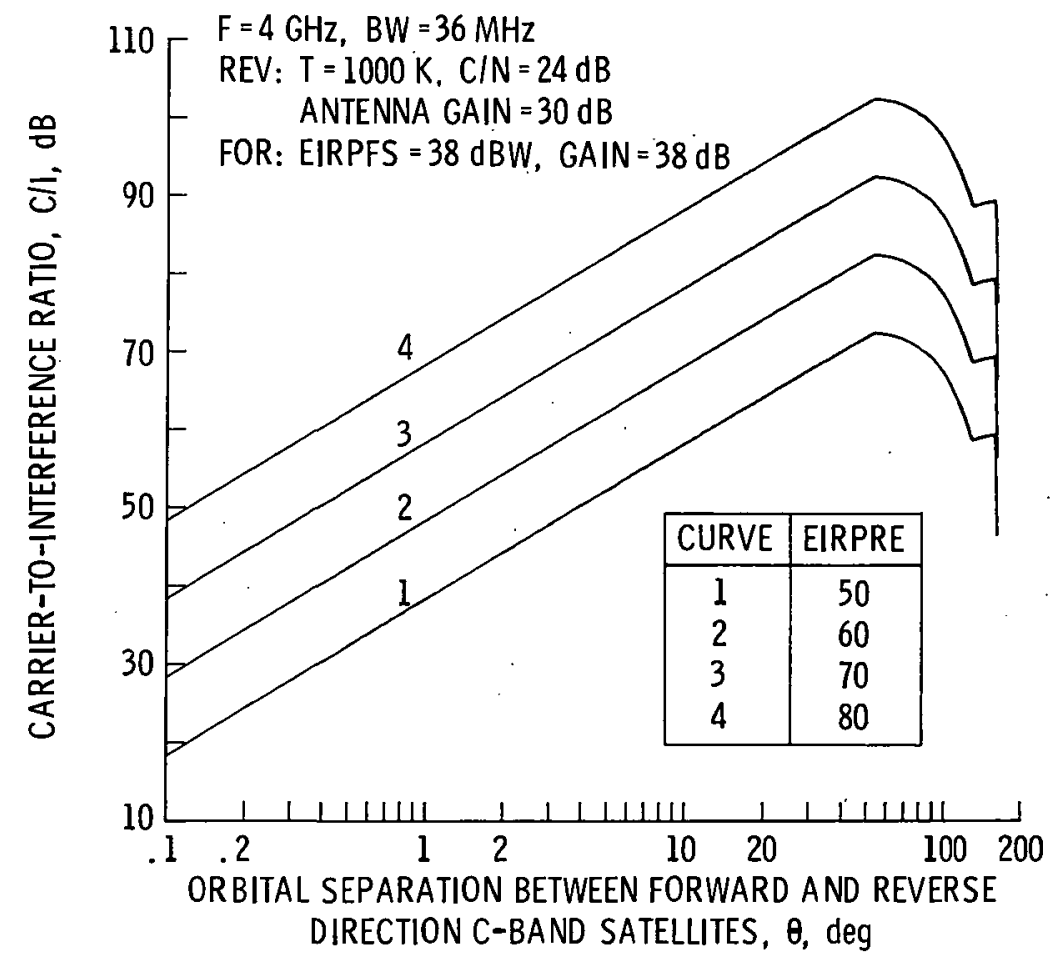

Figure 6. - RBU feeder-link $C / l$ versus $\theta$ dependence on RBU E/S EIRP, EIRPFS = FBU S/C EIRP, EIPRE = RBU EIS EIRP. 


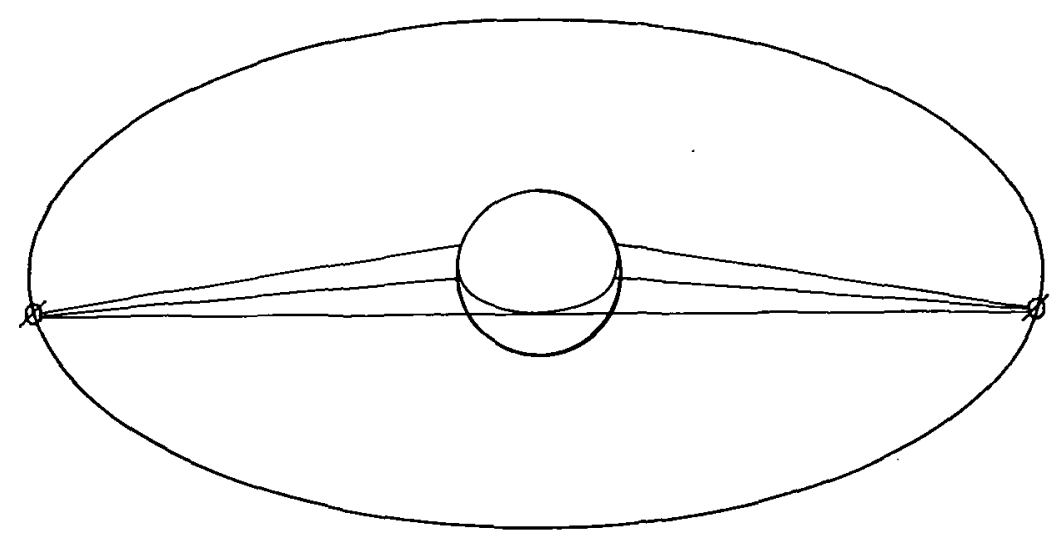

Figure 7. - Interference between nearly antipodal satellites.

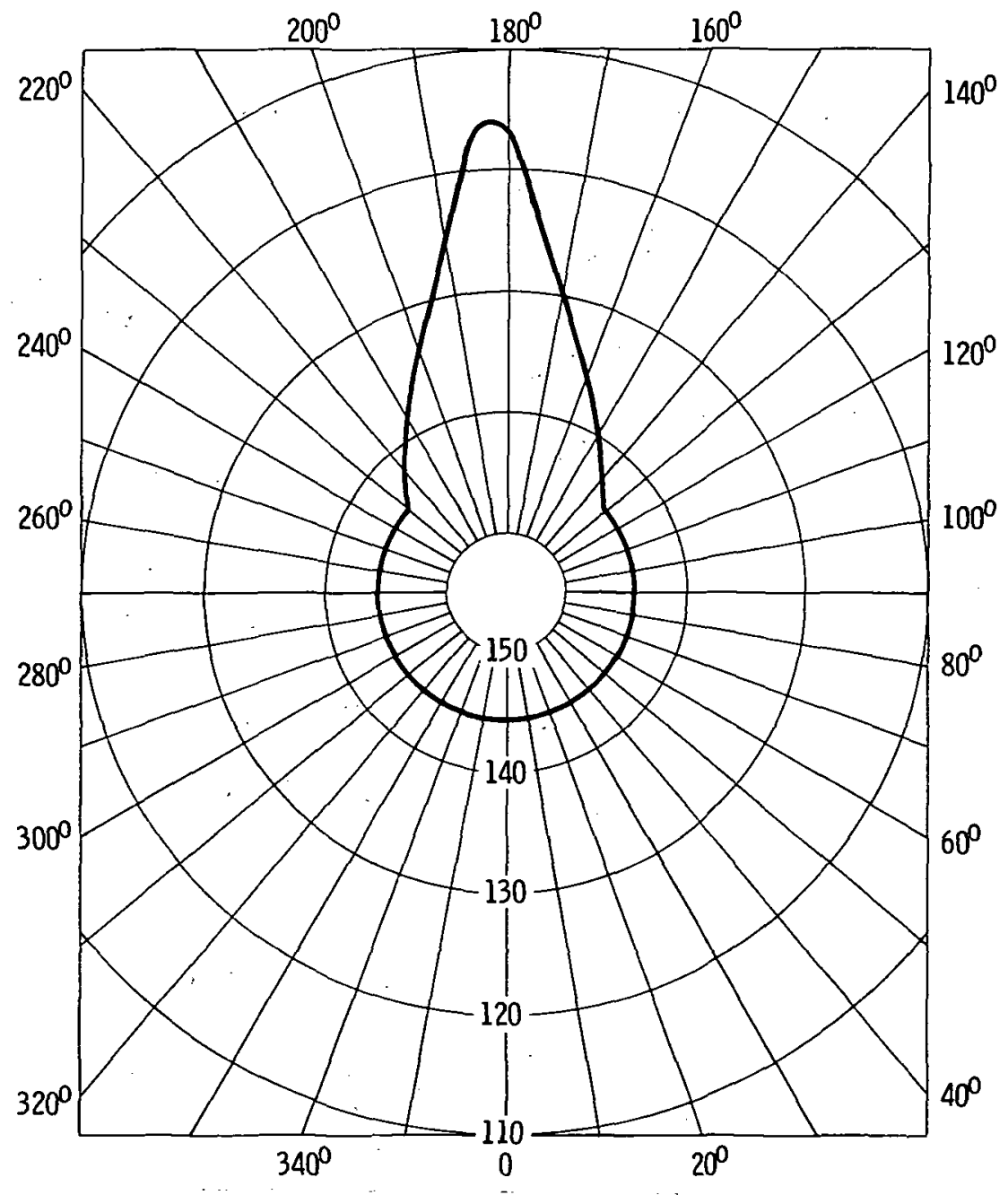

Figure 8. - Polar plot of rain scatter transmission loss versus bistatic angle; $D=3 \mathrm{~m}_{;} E_{2}=3^{0} ; r+d c / 2=10 \mathrm{~km}$; $\mathrm{R}=178.0 \mathrm{~mm} / \mathrm{hr} ; \mathrm{f}=4 \mathrm{GHz}$. 


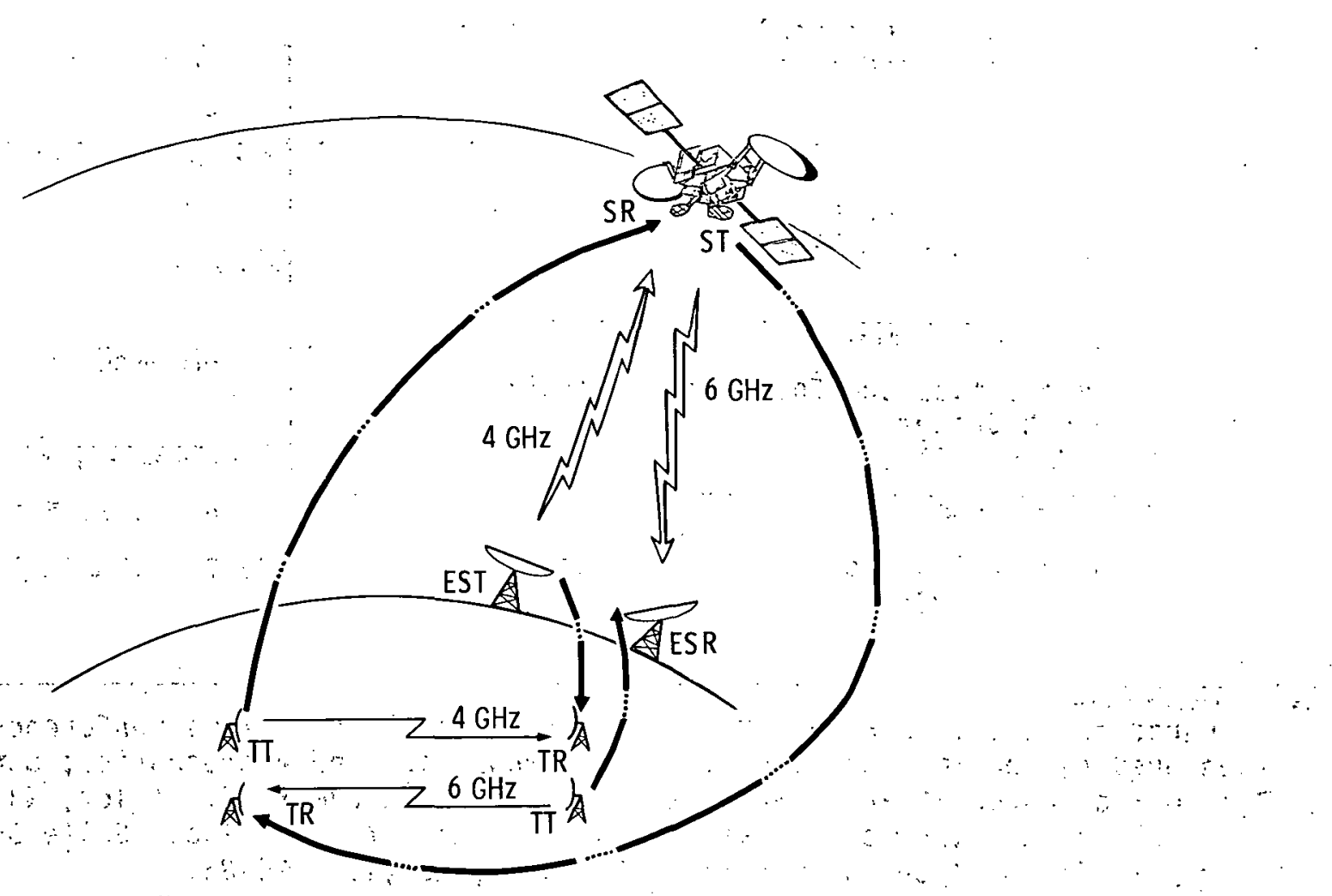

Figure 9. - RBU satellite system and ter restrial systems. 


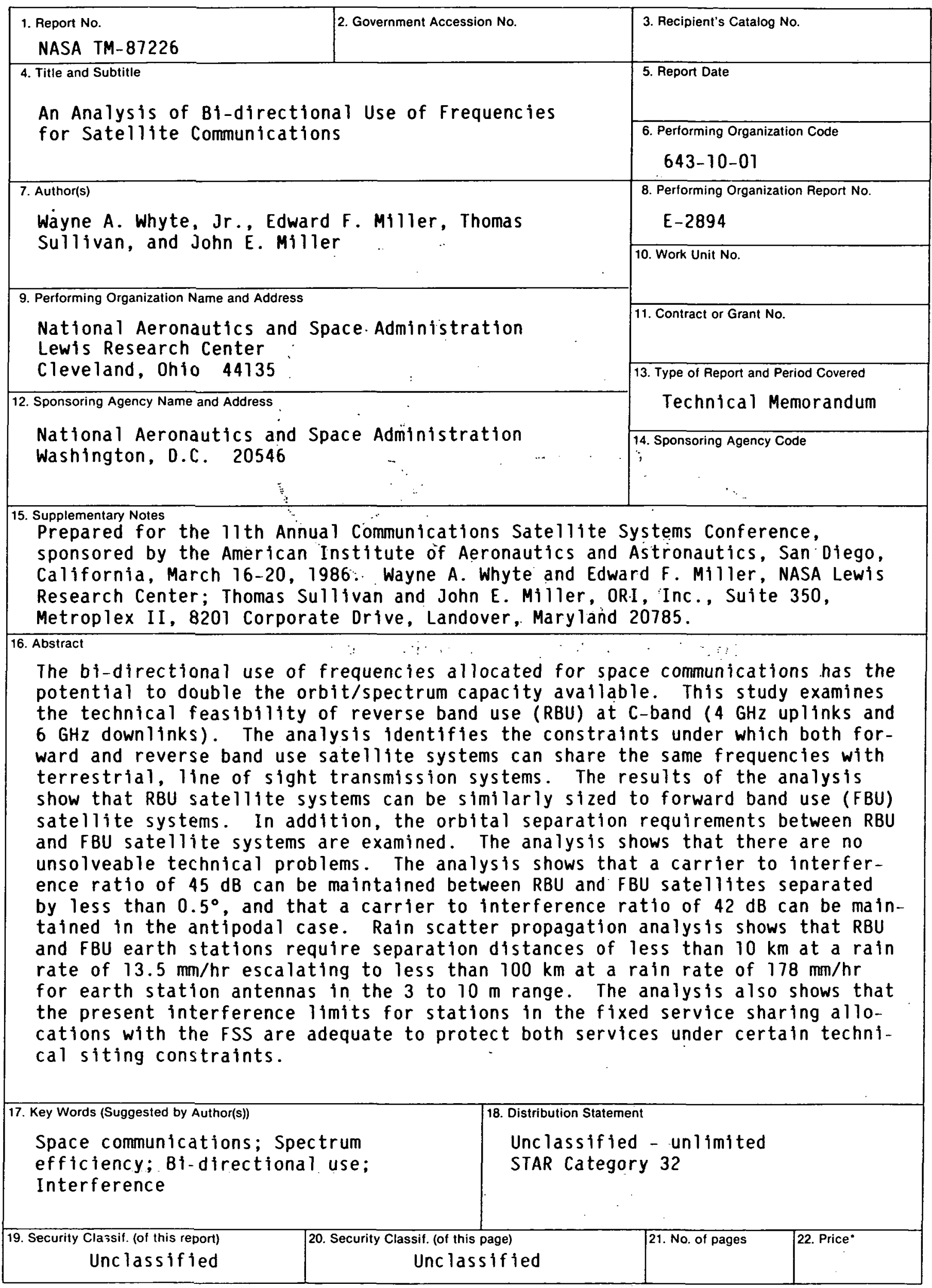

"For sale by the National Technical Information Service, Springfield, Virginia 22161 
National Aeronautics and

Space Administration

Lewis Research Center

Cleveland. Ohio 44135

Official Business

Penalty for Private Use $\$ 300$
SECOND CLASS MAIL

ADORESS CORRECTION REQUESTED

Postage and Fees Paid National Aeronautics and Space Administration NASA.451 